Revista de

Contabilidade e

Organizações

www.rco.usp.br
DOI: http://dx.doi.org/10.11606/issn.1982-6486.rco.2019.152518
Journal of

Accounting and

Organizations

www.rco.usp.br

\title{
O value relevance é relevante?
}

Is the value relevance relevant?

Simone Miranda dos Santos ${ }^{\mathrm{a}}$; Sirlei Lemes ${ }^{\mathrm{a}}$; Flávio Luiz de Moraes Barboza ${ }^{\mathrm{a}}$

${ }^{a}$ Universidade Federal de Uberlândia

Palavras-chave

Meta-análise.

Value relevance.

IFRS.

Qualidade da informação.

\section{Resumo}

A adoção das IFRS pelas companhias de capital aberto no Brasil trouxe a discussão se as referidas normas melhoraram a qualidade das informações contábeis com efeito destas no preço das ações. Os estudos empíricos atualmente demandam uma nova análise dos resultados encontrados sobre o value relevance do lucro líquido (LL) e do patrimônio líquido (PL). Foi realizada uma meta-análise dos estudos publicados sobre o tema, examinando separadamente os modelos de preço e retorno propostos por Ohlson (1995). A amostra constituiu-se de 26 artigos, que analisaram empresas brasileiras no período de 1997 a 2014, totalizando 18.562 observações consideradas pelos artigos que testaram o período pré IFRS e 17.381 observações utilizadas nos testes pós IFRS, para os modelos de preço e retorno. Os resultados indicaram queda do value relevance do PL e ganho na relevância da informação do LL após a adoção das IFRS.

\begin{abstract}
The IFRS adoption by listed companies in Brazil brought the discussion on whether these standards have improved the quality of accounting information through their effect on stock prices. The empirical studies demands a renewed analysis of the accumulated evidences on the value relevance of net income (NI) and shareholders' equity (SE). A meta-analysis of the published studies on the subject was carried out, examining separately the price and return models proposed by Ohlson (1995). The sample consisted of 26 articles that analyzed Brazilian companies from 1997 to 2014, covering 18,562 observations for the pre-IFRS period, and about 17,381 observations for the post IFRS, for the price and return model. The results evidenced a decline in the value relevance of the SE and the gain in the relevance of the NI after the adoption of IFRS.
\end{abstract}

\section{Implicações práticas}

A relevância da informação contábil na Demonstração de Resultado do Exercício varia de acordo com o período de transição para o padrão IFRS. A relevância do lucro líquido e do patrimônio líquido nas diversas fases de adoção não é tão evidente quanto em outros países, e os testes empíricos são sensíveis ao modelo de preço ou retorno adotados para os testes empíricos no tema.

Copyright (C) 2019 FEA-RP/USP. Todos os direitos reservados

\section{INTRODUÇÃO}

A integração mundial dos mercados, motivada pela redução nos custos de comunicação, resultou em uma quase inevitável maior integração dos padrões para elaboração das demonstrações contábeis (Ball, 2006). Essa integração ensejou esforços de organismos e entidades internacionais que resultaram na adoção das normas internacionais de contabilidade (as International Financial Reporting Standards, IFRS) em diversos países. Em maio de 2018, 166 jurisdições já adotaram tais normas (IFRS, 2018), apesar de os processos de adoção se diferenciarem de país a país (Zeff \& Nobes, 2010). 
A busca do International Accounting Standards Board (IASB) pela convergência dos países às IFRS se sustenta no argumento de melhoria da qualidade da informação divulgada pelas empresas num âmbito mundial. Pode-se dizer, assim, que a convergência das normas locais às IFRS resultaria no aumento da qualidade da informação de uma maneira geral. Sob a pressuposição de que a adoção das IFRS resulta na melhoria da qualidade da informação, há um número considerável de pesquisas que busca identificar como este impacto tem sido desenvolvido.

Diversas são as pesquisas que procuram identificar o impacto da adoção das IFRS na relevância, cujos resultados apontam em direções diferentes, senão opostos. Para o lucro líquido (LL) foi constatado aumento no poder de explicar o preço da ação, enquanto, no patrimônio líquido (PL), não houve alteração (Macedo, Machado, Machado \& Mendonça, 2013b). Em contrapartida, em outro estudo foi encontrado que o PL passou a apresentar maior poder explicativo e o LL teve seu poder de explicação reduzido (Gonçalves, Rodrigues \& Macedo, 2014b).

A presente pesquisa busca responder à seguinte questão: qual a influência proporcionada pela adoção das IFRS no value relevance do lucro líquido e patrimônio líquido? Assim, a pesquisa faz uma meta-análise dos estudos empíricos já publicados sobre o tema no Brasil, especificamente observando o impacto no value relevance do LL e do PL. A técnica da meta-análise possibilita combinar resultados de pesquisas diferentes (Bicudo, 2014), e comparar seus achados (Figueiredo Filho, Paranhos, Silva Júnior, Rocha \& Alves Filho, 2014). Foram incluídas na meta-análise 26 artigos publicados em periódicos científicos, o período estudado compreendeu informações financeiras divulgadas entre os anos de 1997 a 2014.

A pesquisa se inspira, em grande parte, na meta-analise realizada por Ahmed, Chalmers e Khlie (2013), que verificou se a adoção das IFRS aumentou a qualidade dos relatórios financeiros e se melhorou o ambiente de informação dos analistas. O estudo em questão concluiu que a adoção das IFRS não aumentou o value relevance do PL, porém aumentou a relevância do LL.

Os benefícios da adoção das IFRS podem ser distintos em diversos mercados (Hail, Leuz \& Wysocki, 2009). Assim, a baixa relevância atribuída pelos investidores à informação divulgada em IFRS indica a necessidade de certa precaução em como interpretar o impacto da adoção das normas em cada país.

A grande diferença em relação a Ahmed et al. (2013) é o foco nas companhias brasileiras. O contexto brasileiro do mercado de ações é marcado pela concentração do mercado, pouca proteção aos acionistas minoritários e excesso de regulamentação são características própria desse mercado (Sarlo Neto, Teixeira, Loss \& Lopes, 2005). Esses fatores, isolados ou conjuntamente, permitem o acesso privilegiado do acionista controlador à informação interna, acentuam conflitos de interesse entre acionistas majoritários e minoritários e geram maior propensão à influência do governo na regulação contábil (Figlioli, 2017), podendo resultar na redução da demanda por informações relevantes pelo mercado.

Assim, o estudo contribui com a literatura internacional analisando as evidências empíricas de value relevance para as particularidades do contexto brasileiro, sobretudo pelo fato do Brasil ter sido o único país a adotar as IFRS em duas etapas.

Iniciativa similar de meta-analise no Brasil foi feita por Damascena, Duarte e Paulo (2017), adotando o modelo de Lipsey e Wilson (2001). O estudo de Damascena et al. (2017) confirmou aumento do value relevance, sendo que o LL se mostrou mais relevante que o PL. O presente estudo inspirado em Ahmed et al. (2013), utiliza um modelo alternativo desenvolvido por Hunter et al. (1982), Hunter e Schmidt (2000) e Rosenthal (1991). Não existe, até onde é do conhecimento dos autores, evidências de superioridade de um modelo em relação ao outro. $\mathrm{O}$ uso de uma técnica distinta da adotada em Damascena et al. (2017) permite validar aqueles resultados ou suscitar novas análises no tema. Ainda, o período aqui observado é ampliado dado que a amostra inclui estudos empíricos mais recentes.

Como a adoção no Brasil foi feita em duas fases, os estudos de value relevance contém três conjuntos diferentes de informações contábeis divulgadas, (i) primeiro, de acordo com as normas contábeis brasileiras antigas (antes de 2008), (ii) segundo, de acordo com 15 pronunciamentos contábeis convergidos para IFRS (2008 e 2009), (iii) terceiro, na adoção total com outros 29 pronunciamentos técnicos, que fazem a adoção total das IFRS (2010 em diante). As amostras dos estudos empíricos em value relevance no Brasil incluem estes diferentes conjuntos de informação. Na presente análise, estas fases são analisadas.

Os resultados da meta-análise indicam a queda do value relevance do PL pós a adoção das IFRS, mas ganho de relevância para o LL. Em particular, o modelo de preço demonstrou que houve redução no value relevance do PL e aumento para o LL em 2007 e redução em 2010. 
Além da validação dos resultados empíricos do tema no Brasil, e a discussão das fases de adoção, o presente estudo permite reduzir o efeito do tamanho das amostras e/ou do período de tempo nos estudos de value relevance no Brasil. A meta-análise ao acumular os resultados estatísticos aumenta o poder de generalização (Ahmed et al., 2013), e aglutina os resultados das pesquisas empíricas sobre value relevance pela adoção das IFRS no Brasil.

\section{PLATAFORMA TEÓRICA}

\subsection{Value relevance}

O objetivo dos relatórios contábeis é fornecer informações sobre a posição patrimonial e financeira de uma empresa, que sejam úteis aos usuários para tomar decisões (CPC 00). Assim, a informação contábil relevante é aquela que influencia a tomada de decisão de seus usuários (Macedo, Machado, Murcia \& Machado, 2011). Por isso, as empresas que possuem melhor nível de divulgação tendem a ser mais valorizadas (Souza \& Borba, 2017).

A relevância é uma das características qualitativas fundamentais da informação contábil (CPC 00). De acordo com este pronunciamento, para a informação ser relevante, ela precisa ter valor preditivo para prognosticar futuros resultados e valor confirmatório para se demonstrar avaliações prévias. As informações contábeis possuem capacidade preditiva mas não existe diferença entre os resultados divulgados antes e após a adoção dos CPC, que são os pronunciamentos contábeis emitidos no Brasil, em tradução às IFRS (Costa \& Afonso, 2015).

Os relatórios contábeis só são relevantes se possuírem associação prevista com o preço das ações (Barth, Beaver \& Landsman, 2001). Assim, as pesquisas sobre value relevance procuram identificar a relação entre o valor de mercado e os dados contábeis, ou seja, a relevância da informação para o mercado (Macedo et al., 2011). Tais pesquisas usam duas teorias distintas da contabilidade: direct valuation e inputs-to-equity-valuation (Holthausen \& Watts, 2001).

Segundo a teoria direct valuations, o lucro contábil destina-se a medir as mudanças ocorridas no valor de mercado das ações, enquanto a teoria inputs-to-equity-valuation apoia-se na ideia de que o papel da contabilidade é fornecer informação para investidores avaliarem o patrimônio da empresa (Holthausen \& Watts, 2001). Consoante a estas teorias, o value relevance pode ser medido por meio da capacidade dos lucros em explicar os retornos anuais dos investimentos realizados nas empresas ajustados a uma taxa de mercado e a capacidade dos valores contábeis do ativo e do passivo para explicar o valor de mercado do PL (Francis \& Schipper, 1999).

O uso dos modelos de value relevance são importantes para identificar se as demonstrações contábeis são uteis para a tomada de decisão dos investidores. Caso contrário, todo o esforço e custo das empresas, para elaborar os relatórios financeiros, podem ser inúteis (Duarte, Girão \& Paulo, 2017). As equações de preço e retorno possuem a capacidade de captar o valor da empresa em função do lucro e do patrimônio líquido (Ohlson, 1995), sendo este um dos modelos mais usados para avaliar a relevância da informação.

Verifica-se, então, que o conceito de value relevance está consolidado, mas o termo tem obtido destaque na literatura recente em função da adoção das IFRS. O processo de convergência dos países às IFRS vem ocorrendo por vários motivos, sendo o principal a melhoria na qualidade da informação contábil e uma das maneiras de avaliá-la é por meio da identificação do value relevance (Baloco \& Almeida, 2017), além de ser uma das proxies mais utilizadas para medir a qualidade da informação contábil (Lubave, Mazzuco \& Nez, 2017).

Os valores contábeis que possuem maior value relevance apresentam melhor qualidade (Barth, Landsman \& Lang, 2008). No contexto das IFRS, o fato pode ser explicado porque a adoção destas normas aproximam as informações contábeis do valor justo de negociação, tornando a informação mais relevante para a tomada de decisão (Ramos \& Lustosa, 2013), uma vez que as informações contábeis são de qualidade, se forem úteis aos interessados (Ball \& Shivakumar, 2005).

Por outro lado, a adoção das IFRS pode resultar em menor qualidade da informação contábil, pois as IFRS podem ser de menor qualidade que os padrões domésticos, resultando em menor value relevance (Barth et al., 2008). Essa situação foi encontrada na Finlândia, onde a mensuração com base nas IFRS dos valores contábeis de ativos e passivos não resultou em maior relevância (Jarva \& Lantto, 2012).

Pode-se deduzir que o benefício da adoção das IFRS não é consenso tanto pela comparação da Norma local com as IFRS quanto pelo processo de adoção das IFRS, que assume diferentes formatos entre os países. Por exemplo, em Israel e África do Sul, aceitam-se as normas como emitidas pelo IASB, enquanto a Austrália segue um processo de várias etapas de implementação (Zeff \& Nobes, 2010). 
Adicionalmente, a concordância sobre os benefícios das IFRS também é afetada pelos modelos de mensuração empregados nas pesquisas, como pode ocorrer com os modelos de retorno e de preço das ações. $\mathrm{O}$ processo de adoção das IFRS é experimentado em cada país de forma muito particular, em função das diferenças legais, econômicas, políticas e institucionais (Santos \& Cavalcante, 2014). Comparando as IFRS com padrões domésticos de ambientes legalistas (code law), elas apresentam melhor substância econômica, lucros e prejuízos de forma mais oportuna, lucros mais informativos, relatórios contábeis mais úteis e reduzem a manipulação de informações pelos gestores (Ball, 2006). Então, a adoção das IFRS pode apresentar efeitos distintos em diferentes sistemas jurídicos, já que a contabilidade é influenciada pelo ambiente em que está inserida (Niyama, 2008).

O impacto da adoção das IFRS está entre as temáticas mais pesquisadas nos principais periódicos internacionais (Ikuno et al., 2012). Os resultados empíricos mostram que a adoção das IFRS está associada ao menor gerenciamento de resultados, maior oportunidade no reconhecimento de perdas e maior value relevance dos valores contábeis de 21 países (Barth et al., 2008) e a maior relevância do LL para investidores de companhias europeias (Barth, Landsman, Young \& Zhuang, 2014). Porém, alguns estudos mostram evidências contrárias ou conflitantes, não identificam aumento do value relevance dos relatórios contábeis (Callao, Jarne \& Laínez,2007) ou impacto positivo no value relevance do LL e do PL, mas apenas nas demonstrações consolidadas (Karampinis \& Hevas, 2009).

Estudos de grupos de países como o G7 e o BRICS também apontam em sentidos diferentes, com aumento simultâneo do value relevance do PL e do LL para alguns países e somente do PL ou do LL para outros (Rodrigues \& Niyama,2016). No cenário brasileiro, os resultados das pesquisas também se contrapõem, pois é possível se deparar com evidências divergentes. A partir da ideia de que características do contexto do país e de seu mercado de capitais, assim como o processo de adoção das IFRS, afetariam o efeito sobre a qualidade da informação, é razoável supor que os estudos, para um mesmo país, deveriam apontar na mesma direção. Todavia, o que se observou foram estudos com evidências divergentes.

A literatura que trata de value relevance das informações contábeis de companhias brasileiras também apresenta resultados conflitantes ou divergentes. Assim, a meta-análise em questão testará as seguintes hipóteses de pesquisa:

$$
\begin{aligned}
& \mathbf{H}_{1} \text { : A adoção das IFRS aumenta o value relevance do lucro líquido. } \\
& \mathbf{H}_{2} \text { : A adoção das IFRS aumenta o value relevance do patrimônio líquido. }
\end{aligned}
$$

\subsection{Etapas de adoção das IFRS no Brasil}

O processo de adoção das IFRS no Brasil é um caso de adoção em fases ou etapas. A seguir discutimos as etapas e os stakeholders envolvidos. O principal produtor de normas contábeis no Brasil é o CPC, órgão criado em 2005 com direcionamento para a convergência total com normas produzidas pelo IASB (Freire, Machado, Machado, Souza, \& Oliveira, 2012).

A adoção das IFRS no Brasil permitiu a quebra da ligação entre as normas contábeis para fins da divulgação e as regras tributárias. A partir dessa quebra foi possível realizar mudanças significativas na prática contábil, pois antes as companhias optavam por abandonar práticas contábeis mais adequadas de acordo com a legislação societária para não ter que adiantar o pagamento de tributos (Black \& Nakao, 2017). Com essa segregação entre as regras contábeis e tributárias foi possível atender melhor a necessidade de cada usuário da informação.

A adoção das IFRS no Brasil ocorreu em duas etapas. A primeira etapa (2008-2009) foi uma fase de transição cobrindo 15 Pronunciamentos Técnicos. A fase desenrolou-se a partir da Lei $\mathrm{n}^{\circ} 11.638$ sancionada em 2007 e a consequente aprovação dos 15 Pronunciamentos Técnicos (Machado, Silva Filho \& Callados, 2014). Neste período, as empresas adotaram parcialmente as IFRS, representadas nos pronunciamentos técnicos. As principais alterações promovidas nos critérios de reconhecimento e mensuração foram a impossibilidade de reavaliação de itens do ativo imobilizado, ajuste a valor presente dos elementos do ativo e passivo exigível a longo prazo, não reconhecimento de itens do ativo diferido, avaliação de investimentos societários dentre outros (Macedo, Araújo \& Braga, 2012).

A segunda etapa (2010- em diante), considerou a adoção total das IFRS. Para este período foram aprovados mais 29 Pronunciamentos Técnicos, com todos os procedimentos conforme as IFRS (Machado et al., 2014). Nesta etapa as companhias de capital aberto foram obrigadas a adotar as novas normas para as demonstrações consolidadas (Freire, et al., 2012). 
A adoção das IFRS resulta em novos critérios de mensuração para elementos patrimoniais resultando em mudanças principalmente no LL e PL (Silva, Martins \& Machado, 2013). Os métodos aplicados para avaliar elementos patrimoniais são de grande importância no que refere-se à confiabilidade e aproximação da informação contábil com a realidade econômica (Grilo, Lachine, Baioco, Reina \& Neto, 2016). Ressalta-se assim a importância de se investigar o impacto da adoção das IFRS no LL e PL.

A transição gradual do Brasil para as IFRS resultou em três conjuntos diferentes de informações contábeis divulgadas: 1) de acordo com as normas contábeis brasileiras antigas, Lei 6.404/76, período anterior a 2008; 2) de acordo com as normas na primeira fase de adoção das IFRS, Lei 11.638/07, que ocorreu em 2008 e 2009 , denominada de adoção parcial, em função da adoção de apenas alguns pontos das IFRS; e 3) de acordo com as IFRS, a partir de 2010 de acordo com a Instrução CVM n. 485/2010, a adoção total, visto que as normas brasileiras se tornam convergentes com as IFRS.

Para trata da adoção por fases, considerando que o objetivo do estudo envolve pesquisas que contemplam os três cenários, por exemplo, Santos e Cavalcante (2014), Martins, Oliveira, Niyama e Dinis (2014b) e Grilo et al. (2016), é feita uma análise adicional das etapas de adoção das IFRS no Brasil.

\section{ASPECTOS METODOLÓGICOS}

\subsection{Seleção da amostra}

Para realizar a meta-análise, foram coletados estudos sobre a relevância da informação após a adoção das IFRS. A fim de identificar estes estudos, realizou-se uma busca com os termos: qualidade da informação, value relevance, relevância da informação, normas internacionais e IFRS. A busca dos trabalhos ocorreu em sites de revistas, anais de congressos e bibliotecas com depositório de dissertações e teses. Com a busca pelos termos, foram encontrados 35 estudos, sendo esta amostra inicial composta de 23 artigos em revistas, seis em congressos, duas teses e quatro dissertações. Nove estudos foram excluídos por não conter dados suficientes para os cálculos, resultando em uma amostra final de 26 estudos, correspondendo a 19 artigos em revistas, quatro em congressos, uma tese e duas dissertações. Essas dissertações e a tese não tinham sido publicadas, em forma de artigos, quando a amostra foi identificada.

A amostra é composta por trabalhos que investigam a relevância da informação no Brasil, sendo esta amostra representativa, quando comparada com a de Ahmed et al. (2013), que foi de 30 estudos para diversos países. A meta-análise considerou os diferentes conteúdos de informação contábil gerados pela adoção em fases das IFRS no Brasil. O procedimento adotado foi dar comparabilidade aos estudos empíricos incluídos na metaanálise, adotando a seguinte taxonomia em relação aos períodos que estes estudos comparavam: "pré-IFRS" e "pós-IFRS". Se o foco do estudo empírico era a fase de adoção parcial das normas, o período "pré-IFRS" se referiu àquele antes de 2008 e o "pós-IFRS" a partir de 2008. Por sua vez, quando no artigo foi investigada a fase de adoção total das IFRS, o período denominado "pré-IFRS" se referiu ao anterior a 2010 e o "pós-IFRS" ao momento posterior a 2010 .

A tabela 1 apresenta os dados empregados no cálculo da meta-análise, reunindo os estudos que recorreram ao modelo de preço e ao modelo de retorno. Como a meta-análise foi realizada por meio da segregação dos estudos que usaram modelos de preços e de retornos, os artigos que usaram os dois modelos foram objeto dos dois cálculos. Nos estudos que apresentaram resultados sem significância estatística ou que não usaram a variável PL no modelo de retorno, foi adotado o valor zero nos cálculos da meta-análise. Os cálculos efetuados para se chegar aos valores dos coeficientes de correlação do PL e LL pré e pós IFRS constantes nas tabelas 1 e 2 são explicados na seção 3.2 ( $1^{\mathrm{a}}$. etapa).

Foi realizada uma análise adicional (item 4.2 Análise das subamostras) considerando os períodos de adoção das IFRS. Para efetivar essa análise, o primeiro passo foi separar os estudos em adoção parcial e adoção total das IFRS, com base na classificação mencionada de pré e pós IFRS.

Na tabela 1 existem trabalhos (Brito, 2016; Brunozi, Ott, Coelho, Menegat \& Webber, 2017; Machado, Macedo \& Machado, 2015; Rodrigue \& Niyama, 2016; Rodrigues, Elias \& Campos, 2015; Siebel, 2013; Silva, 2013; e Silva, Brighenti \& Klann, 2018) em que os dados englobam as duas fases de adoção das IFRS. Para estes estudos foi identificado qual período os autores consideram como pré e pós IFRS, por exemplo, no caso de Brunozi et al. (2017) os autores trataram o ano de 2010 como data de corte da amostra, assim foi considerado pré IFRS período anterior a 2010 e pós período posterior. Logo, a classificação foi realizada de acordo com o ano que os autores realizaram o corte nos dados, 2007 ou 2010. 
No trabalho de Lourenço e Branco (2015a) e Grilo et al. (2016), onde a amostra também engloba as duas fases de adoção das IFRS, foi adotado como pré IFRS período anterior a 2007 e pós IFRS momento posterior a 2010. No trabalho de Lourenço e Branco (2015a) os anos de 2008 e 2009 foram excluídos da amostra por serem anos de adoção parcial. Já no trabalho de Grilo et al. (2016) para o período de adoção parcial os autores realizaram outra análise, não incluída nesta meta-análise. Logo, estes dois últimos trabalhos foram interpretados como avaliação do impacto no value relevance da segunda fase de adoção das IFRS ocorrida em 2010, consoante o tratamento dado pelos autores como efeito da adoção.

Os trabalhos de Santos e Cavalcante (2014) e Martins et al. (2014b) avaliaram as duas fases de adoção das IFRS. Nesta meta-análise foi considerado o corte feito em 2010, pois o resultado encontrado pelos autores das alterações das normas em 2007 foi no mesmo sentido dos incluídos neste estudo.

Em outros trabalhos (Dias, Reina Hehr \& Almeida, 2015; Eng, Lin \& Fiqueiredo, 2014; Ferreira, Lemes \& Forti, 2015; Gonçalves et al., 2014b; Gonçalves, Batista, Macedo \& Marque, 2014a; Macedo et al., 2013b; Martins, Machado \& Callado, 2014a; Potin, Bortolon \& Neto, 2016; Ramos \& Lustosa, 2013; Silva, Conceição \& Dourado, 2015; e Silva et al., 2013) os dados das companhias foram os após 2007, então foi considerado como pré IFRS período anterior a 2010 e pós IFRS período posterior.

Em outros estudos (Macedo et al., 2012; Macedo, Machado \& Machado, 2013a; e Barros, Espejo \& Freitas, 2013) os dados foram referentes a período anterior a 2010, por isso foi tratado pré IFRS período anterior a 2007 e pós IFRS período posterior.

A partir das categorizações dos períodos pré e pós adoção adotados nos estudos da amostra, foi possível classificar os artigos em adoção parcial ou total das IFRS. Para a adoção parcial considerou-se os artigos que realizaram o corte da amostra em 2007 e para a adoção total os artigos que realizaram o corte da amostra em 2010. Com o estudo das fases de adoção das IFRS foi possível analisar os três conjuntos de demonstrações contábeis, pois esta meta-análise é composta por artigos que estudam período anterior a 2008, período de transição (20082009) e o período de adoção total das normas (2010 em diante). 
Tabela 1. Estudos brasileiros em value relevance e coeficientes de correlação do PL e LL pós e pré IFRS

\begin{tabular}{|c|c|c|c|c|c|c|c|c|}
\hline \multirow{2}{*}{ Estudo } & \multirow{2}{*}{ Período } & \multirow{2}{*}{$\begin{array}{l}\text { Fase de } \\
\text { adoção }\end{array}$} & \multirow{2}{*}{ Amostra } & \multicolumn{2}{|c|}{ Coeficientes Pós IFRS } & \multicolumn{2}{|c|}{ Coeficientes Pré IFRS } & \multirow{2}{*}{$\begin{array}{c}\text { Fonte no } \\
\text { artigo origina }\end{array}$} \\
\hline & & & & PL & $\mathbf{L L}$ & PL & $\mathbf{L L}$ & \\
\hline \multicolumn{9}{|l|}{ Estudos brasileiros com o modelo de preço } \\
\hline Macedo et al. (2013a) & 1997-2009 & 2007 & 246 & $0,193 * * *$ & $0,390 * * *$ & $0,307 * * *$ & $0,085^{* *}$ & Tab. 1 e 2 \\
\hline Siebel (2013) & 2001-2012 & 2007 & 51 & 0,064 & $0,059 * * *$ & 0,027 & 0,002 & Tab. 5 \\
\hline Rodrigues et al. (2015) & 2003-2012 & 2007 & 326 & $-0,183 * *$ & $0,167 * *$ & $0,124 *$ & $-0,079 *$ & Tab. 7 e 8 \\
\hline Rodrigue, Niyama (2016) & $2004-2011$ & 2007 & 310 & $0,175 * *$ & $0,181 * *$ & $0,178^{* *}$ & $-0,017$ & Tab. 4 e 5 \\
\hline Macedo et al. (2012) & $2008-2009$ & 2007 & 55 & $0,740 * * *$ & $0,745 * * *$ & $0,641 * * *$ & $0,648 * * *$ & Tab. 1 e 2 \\
\hline Silva (2013) & $2000-2011$ & 2010 & 93 & $-0,142$ & $0,235^{* *}$ & $-0,113$ & $0,295^{*}$ & Tab. 3 \\
\hline Grilo et al. (2016) \# & 2003-2012 & 2010 & 146 & 0,000 & $0,329 * * *$ & 0,000 & $0,329 * * *$ & Tab. 2 \\
\hline Brunozi et al. (2017) & 2003-2014 & 2010 & 219 & 0,076 & $0,181 * * *$ & $0,156^{* *}$ & $0,119^{*}$ & Tab. 3 \\
\hline Lourenço e Branco (2015a) & $2004-2013$ & 2010 & 131 & $0,350 * * *$ & $0,350 * * *$ & $0,350 * * *$ & $0,350 * * *$ & Tab. 4 \\
\hline Machado et al. (2015) & $2005-2011$ & 2010 & 172 & $0,270 * * *$ & $0,175^{* *}$ & $0,304 * * *$ & $0,279 * * *$ & Tab. 2 e 3 \\
\hline Martins et al. (2014b) \# & $2006-2011$ & 2010 & 119 & $0,667 * * *$ & $0,285^{* *}$ & $0,401 * * *$ & $0,667 * * *$ & Tab. 4 e 5 \\
\hline Silva et al. (2018) & $2006-2013$ & 2010 & 274 & $0,242 * * *$ & 0,000 & $0,242 * * *$ & $0,153^{*}$ & Tab. 2 e 3 \\
\hline Brito (2016) & $2006-2014$ & 2010 & 60 & 0,000 & $0,498 * * *$ & $0,498 * * *$ & 0,000 & Tab. 7 \\
\hline Eng et al. (2014) & $2007-2012$ & 2010 & 938 & $0,316^{* * *}$ & $0,502 * * *$ & $0,271 * * *$ & $0,505^{* * *}$ & Tab. 4 \\
\hline Silva et al. (2015) & $2007-2012$ & 2010 & 30 & $0,507 * * *$ & $0,570 * * *$ & $0,520 * * *$ & $0,441 * * *$ & Tab. 5 e 6 \\
\hline Martins et al. (2014a) & $2008-2010$ & 2010 & 719 & $0,148 * *$ & 0,056 & $0,143 * * *$ & $-0,066$ & Tab. 2 e 5 \\
\hline Dias et al. (2015) & $2008-2013$ & 2010 & 133 & $0,560 * * *$ & $-0,149^{*}$ & $0,553 * * *$ & $-0,130$ & Tab. 5 e 6 \\
\hline Potin et al. (2016) & $2008-2013$ & 2010 & 126 & $0,357 * * *$ & $0,228^{*}$ & $0,353 * * *$ & $0,284 * *$ & Tab.3 \\
\hline Gonçalves et al. (2014a) & $2009-2010$ & 2010 & 57 & $0,402 * *$ & $0,599 * *$ & $0,432 * *$ & $0,390 * *$ & Tab. 5 \\
\hline Gonçalves et al. (2014b) & 2009-2010 & 2010 & 24 & $0,696^{* * *}$ & $0,655^{* * *}$ & $0,686 * * *$ & $0,714 * * *$ & Tab. 1 \\
\hline Ramos e Lustosa (2013) & 2009-2010 & 2010 & 210 & $0,928 * * *$ & $0,228 * * *$ & $0,937 * * *$ & $0,377 * * *$ & Tab. 4 \\
\hline Silva et al. (2013) & 2009-2010 & 2010 & 25 & $0,467 * *$ & $0,540 * * *$ & $0,402 * *$ & $0,494 * *$ & Tab. 4 e 5 \\
\hline Ferreira et al. (2015) & 2009-2012 & 2010 & 67 & $0,308^{*}$ & $0,474 * * *$ & $0,308^{*}$ & $0,474 * * *$ & Tab. 3 \\
\hline Macedo el al. (2013b) & 2010-2011 & 2010 & 148 & $0,555^{* * *}$ & $0,454 * * *$ & $0,561 * * *$ & $0,370 * * *$ & Tab. 3 e 4 \\
\hline
\end{tabular}

Fonte: Elaborada pelos autores.

Nota. (\#) Os artigos investigam as duas fases de adoção das IFRS. $\left.(* * *),{ }^{* *}\right)$ e $(*)$ representam a significância estatística dos coeficientes ao nível de $1 \%, 5 \%$ e $10 \%$ respectivamente. 
Tabela 1. Estudos brasileiros em value relevance e coeficientes de correlação do PL e LL pós e pré IFRS (continuação)

\begin{tabular}{|c|c|c|c|c|c|c|c|c|}
\hline \multirow{2}{*}{ Estudo } & \multirow{2}{*}{ Período } & \multirow{2}{*}{$\begin{array}{l}\text { Fase de } \\
\text { adoção }\end{array}$} & \multirow{2}{*}{ Amostra } & \multicolumn{2}{|c|}{ Coeficientes Pós IFRS } & \multicolumn{2}{|c|}{ Coeficientes Pré IFRS } & \multirow{2}{*}{$\begin{array}{c}\text { Fonte no } \\
\text { artigo original }\end{array}$} \\
\hline & & & & PL & $\mathbf{L L}$ & PL & $\mathbf{L L}$ & \\
\hline \multicolumn{9}{|l|}{ Estudos brasileiros com o modelo de retorno } \\
\hline Barros et al. (2013) & $2005-2010$ & 2007 & 30 & $0,208 * *$ & 0,037 & $-0,065$ & $0,179 *$ & Tab. 3 \\
\hline Eng et al. (2014) & $2007-2012$ & 2010 & 938 & 0,000 & $-0,073$ & 0,000 & $0,466 * * *$ & Tab. 4 \\
\hline Ferreira et al.(2015) & $2009-2012$ & 2010 & 67 & 0,000 & $0,474 * * *$ & 0,000 & $0,474 * * *$ & Tab. 2 \\
\hline Santos e Cavalcante (2014) \# & $1999-2013$ & 2010 & 246 & 0,096 & $0,144 * *$ & $-0,065$ & $0,199 * * *$ & Tab. 1 \\
\hline Silva et al. (2018) & $2006-2013$ & 2010 & 274 & $0,242 * * *$ & 0,000 & $0,242 * * *$ & $0,153^{*}$ & Tab. 2 e 3 \\
\hline Brunozi et al. (2017) & $2003-2014$ & 2010 & 219 & 0,000 & $0,161 * *$ & 0,000 & $-0,229 * * *$ & Tab. 2 \\
\hline
\end{tabular}

Fonte: Elaborada pelos autores.

Nota. (\#) Os artigos investigam as duas fases de adoção das IFRS. $\left.(* * *),{ }^{* *}\right)$ e $\left({ }^{*}\right)$ representam a significância estatística dos coeficientes ao nível de $1 \%, 5 \%$ e $10 \%$ respectivamente. 


\subsection{Técnica da meta-análise}

Os cálculos de meta-análise aqui realizados são baseados, em grande parte, nos procedimentos adotados por Ahmed et al. (2013), e se dividem em quatro etapas descritas no Quadro 1.

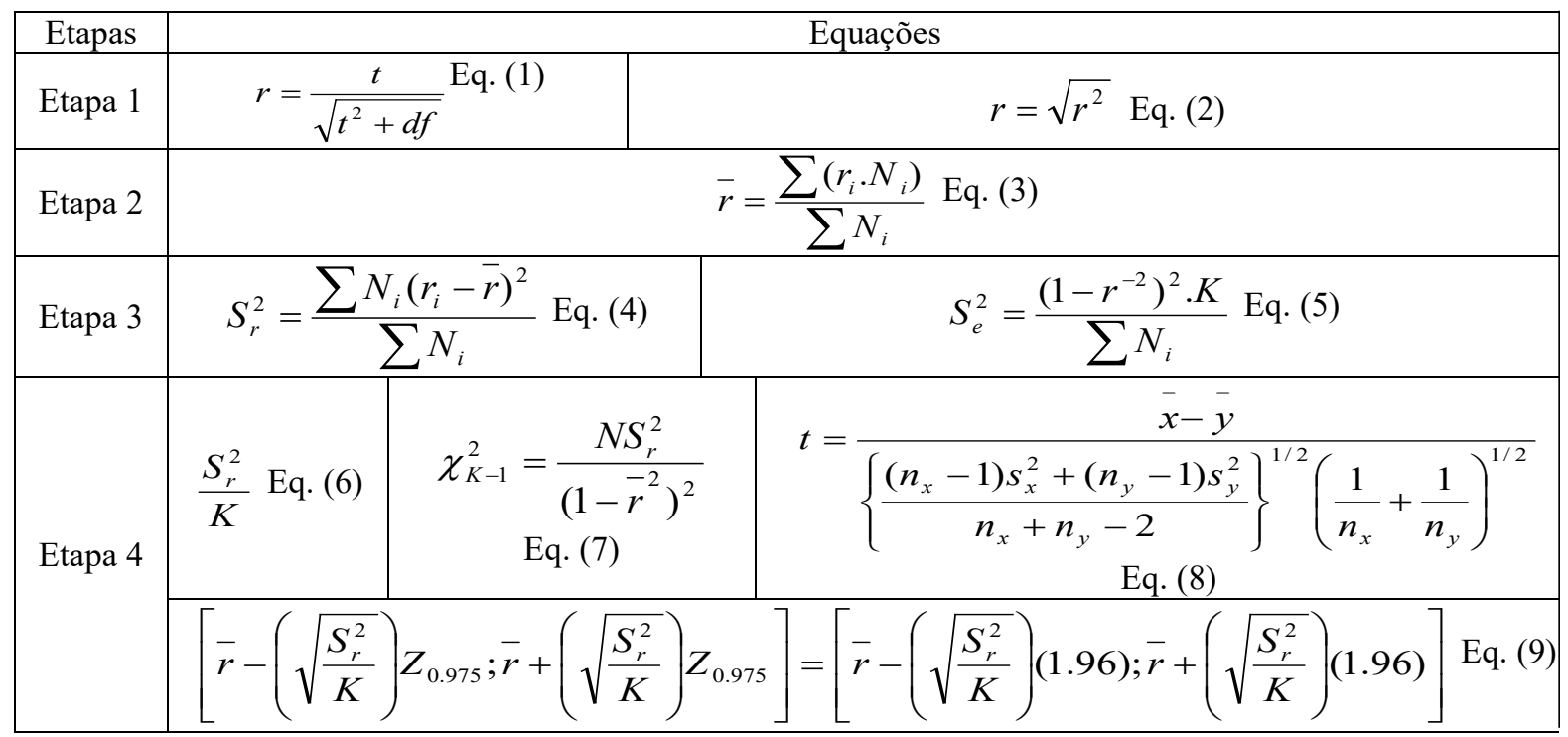

Quadro 1. Equações

Fonte: Elaborada pelos autores.

Nota: Onde $t$ é o valor da estatística $t ; d f$ é o grau de liberdade residuais; $r^{2}$ é o coeficiente de correlação; $r_{i}$ é o coeficiente de correlação de Pearson para o estudo $i ; N_{i}$ é o tamanho da amostra, obtido por meio do número de observações para o estudo $i ; K$ é a quantidade de estudos incluídos na meta-análise; $\bar{x}$ corresponde ao $\bar{r}$ após a adoção das IFRS; $\bar{y}$ é $\bar{r}$ no período anterior a adoção das IFRS; $n_{x}$ número de observações após a adoção das IFRS; $n_{y}$ número de observações antes da adoção das IFRS; $s_{x}^{2}$ corresponde a $S_{r}^{2}$ após a adoção das referidas normas e $s_{y}{ }^{2}$ no período anterior a adoçã̃o.

\section{Primeira etapa}

Realizaram-se conversões das estatísticas encontradas nos estudos da amostra para uma medida de correlação padrão $(r)$. O coeficiente $(r)$ foi selecionado como a métrica para o effect size, porque é uma medida que pode ser utilizada para comparação entre estudos, já que é uma medida padronizada (Matos, 2011) e de fácil entendimento. Entretanto, em muitos trabalhos, esta medida não foi observada. Nesses casos, o $r$ é aproximado conforme os estudos citados anteriormente.

Para os valores da estatística $t$, recorreu-se a Equação (1). Quando os estudos apresentaram o $r^{2}$ foi adotada a Equação (2) para se obter a medida de correlação (Ahmed et al., 2013). Quando o estudo divulgou o p-valor, ele foi convertido em estatística $t$ para, em seguida, ser convertido no coeficiente $r$. As equações são apresentadas no Quadro 1.

\section{Segunda etapa}

O cálculo da correlação média $(\bar{r})$ foi realizado por meio da Equação (3), disponível no Quadro 1.

\section{Terceira etapa}

Os cálculos da variância observada $\left(S_{r}^{2}\right)$ e da variância do erro de amostragem $\left(S_{e}^{2}\right)$ foram efetivados conforme as equações (4) e (5) respectivamente.

\section{Quarta etapa}

A variância que foi empregada para determinar o intervalo de confiança foi obtida por meio da Equação (6). Um intervalo de confiança de $95 \%$ foi adotado para avaliar a validade das associações, conforme a Equação (9). Para testar os efeitos de moderação (teste de homogeneidade) foi utilizado o teste de Qui-quadrado, conforme a Equação (7), com o intuito de determinar se a variância observada é trivial ou superior ao esperado. Para constatar as diferenças nas médias $(t)$, usou-se a Equação 8 conforme Statacorp (2015). 


\section{RESULTADOS E ANÁLISE}

Na seção 4.1, são relatados os resultados da pesquisa e suas principais análises, considerando a amostra dos estudos em seu todo. Na seção 4.2, são dispostas as análises adicionais contemplando os cálculos para subamostras dos períodos de adoção parcial e total das IFRS.

\subsection{Análise da amostra Completa: antes e depois das IFRS}

Quando investigado se houve aumento ou redução do PL e LL após a adoção das IFRS, com base nos coeficientes de correlação encontrados nos estudos (Tabela 1) pelo modelo de preço, é possível constatar que houve aumento do PL em nove artigos e redução em 11. Em relação ao LL, foi identificada redução em oito artigos e aumento em 13. Diante disso, supõe-se que ocorreu perda do value relevance para o PL e ganho para o LL após a adoção das referidas normas.

A Tabela 2 retrata os resultados da meta-análise com foco no LL antes e após a adoção das IFRS. O teste de homogeneidade é rejeitado para os dois períodos. Pela análise do $\bar{r}$ global, identifica-se aumento do LL no período posterior à adoção das normas, passando de 0,1223 para 0,1808. Estes resultados estão de acordo com o encontrado por Ahmed et al. (2013), que verificaram movimento crescente na relevância do LL.

Tabela 2. Efeito no Lucro

\begin{tabular}{|c|c|c|c|c|c|c|c|c|c|c|}
\hline Modelos & $\begin{array}{l}\text { Obs. } \\
\text { (n) }\end{array}$ & $K$ & $\bar{r}$ & $S_{r}^{2}$ & $S_{e}^{2}$ & $S_{r}^{2} / S_{e}^{2}$ & $Z$ & $\begin{array}{l}\text { Intervalo de } \\
\text { confiança }\end{array}$ & $X_{k-1}^{2}$ & Student-T \\
\hline \multicolumn{11}{|l|}{ Pré IFRS } \\
\hline $\begin{array}{l}\text { Regressão } \\
\text { Completa }\end{array}$ & 18562 & 30 & 0,1223 & 0,0446 & 0,0016 & 3,5188 & 3,1718 & 0,$0467 ; 0,1978$ & 852,5523 & $30,0099 * * *$ \\
\hline Preço & 13874 & 24 & 0,1421 & 0,0357 & 0,0017 & 4,6503 & 3,6829 & 0,$0665 ; 0,2177$ & 516,0948 & $26,7800 * * *$ \\
\hline Retorno & 4688 & 6 & 0,0636 & 0,0662 & 0,0013 & 1,9185 & 0,6056 & $-0,1422 ; 0,2694$ & 312,7386 & $18,0880 * * *$ \\
\hline \multicolumn{11}{|l|}{ Pós IFRS } \\
\hline $\begin{array}{l}\text { Regressão } \\
\text { Completa }\end{array}$ & 17381 & 30 & 0,1808 & 0,0230 & 0,0016 & 7,0200 & 6,5281 & 0,$1265 ; 0,2351$ & 427,3488 & \\
\hline Preço & 12143 & 24 & 0,2014 & 0,0274 & 0,0018 & 6,6350 & 5,9601 & 0,$1352 ; 0,2677$ & 361,7165 & \\
\hline Retorno & 5238 & 6 & 0,1329 & 0,0095 & 0,0011 & 11,6507 & 3,3408 & 0,$0549 ; 0,2108$ & 51,4993 & \\
\hline
\end{tabular}

Fonte: Elaborada pelos autores.

Nota: $* \mathrm{p}<0,05 * * \mathrm{p}<0,01 * * * \mathrm{p}<0,001$. A seleção dos artigos para compor este teste foi realizada de acordo com a coluna 'Fase de adoção das IFRS' da Tabela 1. A regressão completa é formada pela soma dos artigos do modelo de preço com o modelo de retorno. O modelo de preço é composto pelos 19 artigos (que estudam a adoção em 2010) mais cinco artigos (que estudam a adoção em 2007), sendo os 24 artigos listados na Tabela 1. O modelo de retorno é composto por cinco artigos (que estudam a adoção em 2010) mais um artigo (que estuda a adoção em 2007), sendo os seis listados na Tabela 1.

A fim de averiguar se ocorreu aumento do value relevance após a adoção das normas, a coluna Student-T da Tabela 2 exibe o grau de igualdade para o LL no período pré e pós IFRS. No modelo de preço, retorno e resultado para a regressão completa, ocorreu aumento significativo do value relevance para o LL após a adoção das IFRS, confirmando as evidências Ahmed et al. (2013) e Damascena et al. (2017).

Os resultados da Tabela 3 fornecem evidências do estudo em relação ao PL. O teste de homogeneidade é rejeitado para os dois períodos. Os resultados para a regressão completa indicam que o $\bar{r}$ reduziu $(0,1774$ para 0,1480) após a adoção das IFRS, sinalizando queda na relevância da informação do PL, similar ao encontrado por Ahmed et al. (2013). 
Tabela 3. Efeito no patrimônio líquido

\begin{tabular}{|c|c|c|c|c|c|c|c|c|c|c|}
\hline Modelos & $\begin{array}{l}\text { Obs. } \\
\text { (n) }\end{array}$ & $K$ & $\bar{r}$ & $S_{r}^{2}$ & $S_{e}^{2}$ & $S_{r}^{2} / S_{e}^{2}$ & $Z$ & $\begin{array}{c}\text { Intervalo de } \\
\text { confiança }\end{array}$ & $X_{k-1}^{2}$ & Student-T \\
\hline \multicolumn{11}{|l|}{ Pré IFRS } \\
\hline $\begin{array}{l}\text { Regressão } \\
\text { Completa }\end{array}$ & 18562 & 30 & 0,1774 & 0,0367 & 0,0015 & 4,1325 & 5,0716 & 0,$1088 ; 0,2459$ & 725,9469 & $-13,675^{* * *}$ \\
\hline Preço & 13874 & 24 & 0,2411 & 0,0313 & 0,0015 & 4,9020 & 6,6766 & 0,$1703 ; 0,3119$ & 489,5985 & $-22,371 * * *$ \\
\hline Retorno & 4688 & 6 & $-0,011$ & 0,0050 & 0,0013 & 25,8168 & $-0,396$ & $-0,0677 ; 0,0449$ & 23,2407 & $59,5177 * * *$ \\
\hline \multicolumn{11}{|l|}{ Pós IFRS } \\
\hline $\begin{array}{l}\text { Regressão } \\
\text { Completa }\end{array}$ & 17381 & 30 & 0,1480 & 0,0466 & 0,0017 & 3,5409 & 3,7525 & 0,$0707 ; 0,2252$ & 847,2492 & \\
\hline Preço & 12143 & 24 & 0,1820 & 0,0611 & 0,0018 & 3,0227 & 3,6065 & 0,$0831 ; 0,2809$ & 793,9994 & \\
\hline Retorno & 5238 & 6 & 0,0690 & 0,0041 & 0,0011 & 27,5699 & 2,6343 & 0,$0177 ; 0,1203$ & 21,7629 & \\
\hline
\end{tabular}

Fonte: Elaborada pelos autores.

Nota: $* \mathrm{p}<0,05 * * \mathrm{p}<0,01 * * * \mathrm{p}<0,001$. A seleção dos artigos para compor este teste foi realizada de acordo com a coluna 'Fase de adoção das IFRS' da Tabela 1. A regressão completa é formada pela soma dos artigos do modelo de preço com o modelo de retorno. O modelo de preço é composto pelos 19 artigos (que estudam a adoção em 2010) mais cinco artigos (que estudam a adoção em 2007), sendo os 24 artigos listados na Tabela 1. O modelo de retorno é composto por cinco artigos (que estudam a adoção em 2010) mais um artigo (que estuda a adoção em 2007), sendo os seis listados na Tabela 1.

A coluna Student-T representa o resultado análogo da Tabela 2, porém atenta-se para o PL. No caso do modelo de preço, ocorreu redução significativa do $\bar{r}$ (de 0,2411 a 0,1820 e $t=-22,3714$ ). A queda da relevância da informação do PL, após a adoção das IFRS, é também evidenciada por Brito (2016), Grillo et al. (2016) e Macedo et al. (2013a).

No modelo de retorno (Tabela 3), houve aumento significativo do $\bar{r}$ (de $-0,0114$ a $0,0690, t=59,5177$ ) para a relevância do PL. Este resultado é limitado, pois foram encontrados apenas seis estudos (23,08\% da amostra) que usaram este modelo. Dentre eles, três não examinaram a variável PL e, por isso, adotou-se zero. Apesar disso, existem pesquisas que identificaram aumento da relevância do PL após a adoção da norma, como em Gonçalves et al. (2014b), Silva et al. (2018) e Rodrigues e Niyama (2016).

Constatou-se, conforme ainda Ahmed et al. (2013), que a relevância do PL não aumentou após a adoção das IFRS, havendo, ao contrário, redução significativa no resultado para a regressão completa apesar de ser diferente do de Damascena et al. (2017), que identificaram aumento do conteúdo informacional do PL pós IFRS.

Em alguns estudos foi adotado zero para o desenvolvimento da meta-análise. Tal ação ocorreu quando os autores apresentaram resultados para apenas uma variável do modelo e naqueles em que não houve significância estatística em algum período. Para maior confiança nos resultados, foi realizado um teste excluindo os estudos onde ocorreu a adoção do zero, o qual constatou indiferença. Adicionalmente, foram excluídos os valores negativos, conforme Ahmed et al. (2013). Os resultados também permaneceram inalterados.

A partir das análises explicitadas, evidencia-se que os resultados suportam a Hipótese 1, de que a adoção das IFRS aumenta o value relevance do LL. Todavia os resultados não suportam a Hipótese 2, com respeito à adoção das IFRS aumentar o value relevance do PL. Estes resultados corroboram os encontrados por Ahmed et al. (2013), o que evidencia que a adoção das IFRS no Brasil segue movimento semelhante a outros países.

A redução da relevância do PL, pode ser justificada em função da crise mundial de 2008, também ao fato que o PL é uma variável de característica mais estável, por isso, não conseguiu acompanhar o preço das ações, reduzindo sua relevância (Macedo et al. 2013a). A perda do value relevance do PL pode ter ocorrido ainda pela adoção do valor justo, uma vez que este método é mais subjetivo quando comparado com a objetividade do custo histórico, resultando em menor confiança do mercado nas informações apresentadas. (Grillo et al. 2016),

O ganho no value relevance do LL pode estar associado à redução no conservadorismo e a introdução do conceito do valor justo, pois estes aproximam a informação contábil do valor de mercado (Macedo et al., 2013). Também pode estar relacionado ao fato de as IFRS serem normas voltadas para o mercado de capitas (Gonçalves et al., 2014a). Adicionalmente, a adoção das normas possibilita a comparação das informações contábeis pelos investidores, o que pode justificar o aumento da relevância (Barros et al., 2013). 


\subsection{Análise adicional: subamostras da adoção parcial vs adoção total das IFRS}

Foram realizados testes adicionais levando em conta as etapas de adoção das IFRS. A primeira etapa ocorreu a partir da Lei n 11.638 em 2007, a segunda etapa a partir da Instrução CVM n. 485/2010. Os dados foram separados em adoção parcial em 2007 e adoção total em 2010. Para a análise da adoção parcial, foram considerados os estudos que fazem a separação pré e pós IFRS no ano de 2007.

Em relação ao PL e com uso do modelo de preço, para o período de adoção parcial, foi identificada redução significativa da relevância da informação ( $\bar{r}$ de 0,1988 para 0,0198 , com $t=-55,3779)$. Para o LL, houve aumento significativo após a adoção parcial das normas ( $\bar{r}$ de 0,0053 para 0,2008 , com $t=88,7481)$, de acordo com a Tabelas 4 e 5. O teste de homogeneidade foi rejeitado para o LL e PL nos dois períodos. Para o modelo de retorno, não foi possível efetuar a análise da adoção parcial, pois foi encontrado apenas um estudo para este período.

Tabela 4. Resultados para adoção parcial das IFRS em 2007 - Efeito no lucro líquido

\begin{tabular}{|c|c|c|c|c|c|c|c|c|c|c|}
\hline Modelos & $\begin{array}{l}\text { Obs. } \\
\text { (n) }\end{array}$ & K & $\bar{r}$ & $S_{r}^{2}$ & $S_{e}^{2}$ & $S_{r}^{2} / S_{e}^{2}$ & $Z$ & $\begin{array}{c}\text { Intervalo de } \\
\text { confiança }\end{array}$ & $X_{k-1}^{2}$ & Student-T \\
\hline \multicolumn{11}{|l|}{ Pré IFRS } \\
\hline $\begin{array}{l}\text { Regressão } \\
\text { Completa }\end{array}$ & 4954 & 6 & 0,0084 & 0,0097 & 0,0012 & 12,4908 & 0,2098 & $-0,0704 ; 0,0872$ & 48,0354 & $84,997 * * *$ \\
\hline Preço & 4864 & 5 & 0,0053 & 0,0093 & 0,0010 & 11,0231 & 0,1222 & $-0,0794 ; 0,0899$ & 45,3592 & $88,7481^{* * *}$ \\
\hline Retorno & - & - & - & - & - & - & - & - & - & - \\
\hline \multicolumn{11}{|l|}{ Pós IFRS } \\
\hline $\begin{array}{l}\text { Regressão } \\
\text { Completa }\end{array}$ & 3813 & 6 & 0,1969 & 0,0118 & 0,0015 & 12,3556 & 4,4467 & 0,$1101 ; 0,2837$ & 48,5611 & \\
\hline Preço & 3723 & 5 & 0,2008 & 0,0114 & 0,0012 & 10,8295 & 4,2009 & 0,$1071 ; 0,2945$ & 46,1701 & \\
\hline Retorno & - & - & - & - & - & - & - & - & - & \\
\hline
\end{tabular}

Fonte: Elaborada pelos autores.

Nota: $* \mathrm{p}<0,05 * * \mathrm{p}<0,01 * * * \mathrm{p}<0,001$. A seleção dos artigos para compor este teste foi realizada de acordo com a coluna 'Fase de adoção das IFRS' da Tabela 1. A regressão completa é formada pela soma dos artigos do modelo de preço com o modelo de retorno. O modelo de preço é composto pelos 19 artigos (que estudam a adoção em 2010) mais cinco artigos (que estudam a adoção em 2007), sendo os 24 artigos listados na Tabela 1. O modelo de retorno é composto por cinco artigos (que estudam a adoção em 2010) mais um artigo (que estuda a adoção em 2007), sendo os seis listados na Tabela 1.

Tabela 5. Resultados para adoção parcial das IFRS em 2007 - Efeito no patrimônio líquido

\begin{tabular}{|c|c|c|c|c|c|c|c|c|c|c|}
\hline Modelos & $\begin{array}{c}\text { Obs. } \\
\text { (n) }\end{array}$ & $K$ & $\bar{r}$ & $S_{r}^{2}$ & $S_{e}^{2}$ & $S_{r}^{2} / S_{e}^{2}$ & $Z$ & $\begin{array}{c}\text { Intervalo de } \\
\text { confiança }\end{array}$ & $X_{k-1}^{2}$ & Student-T \\
\hline \multicolumn{11}{|l|}{ Pré IFRS } \\
\hline $\begin{array}{l}\text { Regressão } \\
\text { Completa }\end{array}$ & 4954 & 6 & 0,1940 & 0,0110 & 0,0011 & 10,1912 & 4,5306 & 0,$1101 ; 0,2780$ & 58,8744 & $-52,376^{* * *}$ \\
\hline Preço & 4864 & 5 & 0,1988 & 0,0099 & 0,0009 & 9,5334 & 4,4578 & 0,$1114 ; 0,2863$ & 52,4474 & $-55,377 * * *$ \\
\hline Retorno & - & - & - & - & - & - & - & - & - & - \\
\hline \multicolumn{11}{|l|}{ Pós IFRS } \\
\hline $\begin{array}{l}\text { Regressão } \\
\text { Completa }\end{array}$ & 3813 & 6 & 0,0243 & 0,0377 & 0,0016 & 4,1647 & 0,3063 & $-0,1312 ; 0,1797$ & 144,0697 & \\
\hline Preço & 3723 & 5 & 0,0198 & 0,0378 & 0,0013 & 3,5487 & 0,2282 & $-0,1506 ; 0,1903$ & 140,8970 & \\
\hline Retorno & - & - & - & - & - & - & - & - & - & \\
\hline
\end{tabular}

Fonte: Elaborada pelos autores.

Nota: $* \mathrm{p}<0,05 * * \mathrm{p}<0,01 * * * \mathrm{p}<0,001$. A seleção dos artigos para compor este teste foi realizada de acordo com a coluna 'Fase de adoção das IFRS' da Tabela 1. A regressão completa é formada pela soma dos artigos do modelo de preço com o modelo de retorno. O modelo de preço é composto pelos 19 artigos (que estudam a adoção em 2010) mais cinco artigos (que estudam a adoção em 2007), sendo os 24 artigos listados na Tabela 1. O modelo de retorno é composto por cinco artigos (que estudam a adoção em 2010) mais um artigo (que estuda a adoção em 2007), sendo os seis listados na Tabela 1. 
Na análise do período de adoção total, em 2010, consideraram-se os estudos que realizaram a separação em pré e pós IFRS em 2010, excluindo os artigos que usaram os dados de 2007, sendo esta a diferença para os resultados da amostra total. O efeito da adoção total das IFRS para o PL no modelo de preço evidencia redução significativa da relevância da informação ( $\bar{r}$ de 0,2640 para 0,2537 , com $t=-3,0948)$. O modelo de retorno revela aumento significativo da relevância do PL ( $\bar{r}$ de $-0,0103$ para 0,0666, com $t=57,2212)$, conforme Tabelas 6 e 7 . Em relação ao LL, no modelo de preço, foi encontrado redução significativa $(\bar{r}$ de 0,2159 para 0,2018, com $t=-5,0352)$ e no modelo de retorno foi identificado aumento significativo do LL ( $\bar{r}$ de 0,0613 para 0,1345 , com $t=18,8208)$. O teste de homogeneidade foi rejeitado para os dois períodos.

Tabela 6. Resultados para adoção parcial das IFRS em 2010 - Efeito no lucro líquido

\begin{tabular}{|c|c|c|c|c|c|c|c|c|c|c|}
\hline Modelos & $\begin{array}{c}\text { Obs. } \\
\text { (n) }\end{array}$ & $K$ & $\bar{r}$ & $S_{r}^{2}$ & $S_{e}^{2}$ & $S_{r}^{2} / S_{e}^{2}$ & $Z$ & $\begin{array}{c}\text { Intervalo de } \\
\text { confiança }\end{array}$ & $X_{k-1}^{2}$ & Student-T \\
\hline \multicolumn{11}{|l|}{ Pré IFRS } \\
\hline $\begin{array}{l}\text { Regressão } \\
\text { Completa }\end{array}$ & 13608 & 24 & 0,1637 & 0,0508 & 0,0017 & 3,2863 & 3,5568 & 0,$0735 ; 0,2539$ & 730,3027 & $5,2763 * * *$ \\
\hline Preço & 9010 & 19 & 0,2159 & 0,0344 & 0,0019 & 5,5715 & 5,0742 & 0,$1325 ; 0,2993$ & 341,0188 & $-5,0352 * * *$ \\
\hline Retorno & 4598 & 5 & 0,0613 & 0,0672 & 0,0011 & 1,6060 & 0,5291 & $-0,1659 ; 0,2886$ & 311,3265 & $18,8208^{* * *}$ \\
\hline \multicolumn{11}{|l|}{ Pós IFRS } \\
\hline $\begin{array}{l}\text { Regressão } \\
\text { Completa }\end{array}$ & 13568 & 24 & 0,1762 & 0,0261 & 0,0017 & 6,3699 & 5,3473 & 0,$1116 ; 0,2408$ & 376,7742 & \\
\hline Preço & 8420 & 19 & 0,2018 & 0,0345 & 0,0021 & 6,0203 & 4,7351 & 0,$1182 ; 0,2853$ & 315,5966 & \\
\hline Retorno & 5148 & 5 & 0,1345 & 0,0095 & 0,0009 & 9,8656 & 3,0874 & 0,$0491 ; 0,2199$ & 50,6810 & \\
\hline
\end{tabular}

Fonte: Elaborada pelos autores.

Nota: $* \mathrm{p}<0,05 * * \mathrm{p}<0,01 * * * \mathrm{p}<0,001$. A seleção dos artigos para compor este teste foi realizada de acordo com a coluna 'Fase de adoção das IFRS' da Tabela 1. A regressão completa é formada pela soma dos artigos do modelo de preço com o modelo de retorno. O modelo de preço é composto pelos 19 artigos (que estudam a adoção em 2010) mais cinco artigos (que estudam a adoção em 2007), sendo os 24 artigos listados na Tabela 1. O modelo de retorno é composto por cinco artigos (que estudam a adoção em 2010) mais um artigo (que estuda a adoção em 2007), sendo os seis listados na Tabela 1.

Tabela 7. Resultados para adoção parcial das IFRS em 2010 - Efeito no patrimônio líquido

\begin{tabular}{|c|c|c|c|c|c|c|c|c|c|c|}
\hline Modelos & $\begin{array}{l}\text { Obs. } \\
\text { (n) }\end{array}$ & $K$ & $\bar{r}$ & $S_{r}^{2}$ & $S_{e}^{2}$ & $S_{r}^{2} / S_{e}^{2}$ & $Z$ & $\begin{array}{l}\text { Intervalo de } \\
\text { confiança }\end{array}$ & $X_{k-1}^{2}$ & Student-T \\
\hline \multicolumn{11}{|l|}{ Pré IFRS } \\
\hline $\begin{array}{l}\text { Regressão } \\
\text { Completa }\end{array}$ & 13608 & 24 & 0,1713 & 0,0459 & 0,0017 & 3,6204 & 3,9166 & 0,$0856 ; 0,2570$ & 662,9147 & $4,4502 * * *$ \\
\hline Preço & 9010 & 19 & 0,2640 & 0,0413 & 0,0018 & 4,4142 & 5,6585 & 0,$1725 ; 0,3554$ & 430,4293 & $-3,0948 * * *$ \\
\hline Retorno & 4598 & 5 & $-0,010$ & 0,0050 & 0,0011 & 21,7602 & $-0,327$ & $-0,0723 ; 0,0516$ & 22,9777 & $57,2212 * * *$ \\
\hline \multicolumn{11}{|l|}{ Pós IFRS } \\
\hline $\begin{array}{l}\text { Regressão } \\
\text { Completa }\end{array}$ & 13568 & 24 & 0,1827 & 0,0436 & 0,0017 & 3,7881 & 4,2850 & 0,$0991 ; 0,2663$ & 633,5632 & \\
\hline Preço & 8420 & 19 & 0,2537 & 0,0547 & 0,0020 & 3,6135 & 4,7300 & 0,$1486 ; 0,3588$ & 525,8018 & \\
\hline Retorno & 5148 & 5 & 0,0666 & 0,0038 & 0,0010 & 25,0489 & 2,4008 & 0,$0122 ; 0,1209$ & 19,9609 & \\
\hline
\end{tabular}

Fonte: Elaborada pelos autores.

Nota: $* \mathrm{p}<0,05 * * \mathrm{p}<0,01 * * * \mathrm{p}<0,001$. A seleção dos artigos para compor este teste foi realizada de acordo com a coluna 'Fase de adoção das IFRS' da Tabela 1. A regressão completa é formada pela soma dos artigos do modelo de preço com o modelo de retorno. O modelo de preço é composto pelos 19 artigos (que estudam a adoção em 2010) mais cinco artigos (que estudam a adoção em 2007), sendo os 24 artigos listados na Tabela 1. O modelo de retorno é composto por cinco artigos (que estudam a adoção em 2010) mais um artigo (que estuda a adoção em 2007), sendo os seis listados na Tabela 1.

A Tabela 8 demonstra os resultados totais da pesquisa. Ela sintetiza os resultados reportados nas Tabelas 2 a 7, e correspondem a coluna Student- $T$ daquelas tabelas. Se o resultado do teste foi positivo adotou-se o sinal (+) e quando negativo adotou-se o sinal (-). Nota-se que os resultados são bem diferentes em relação ao modelo de preço e de retorno. Usando a regressão completa, reunindo os modelos de preços e de retorno, o a relevância do LL aumenta nos três períodos. Contudo, se a análise é feita apenas no modelo de preço, houve queda na fase de adoção total. Já para o PL, analisando a 'regressão completa' houve redução do value relevance na adoção parcial e aumento na fase de adoção total. Se considerado o modelo de preço apenas, houve queda nas duas fases. 
Tabela 8. Resumo dos resultados comparando as duas fases de adoção - parcial e total

\begin{tabular}{|c|c|c|c|c|c|c|c|c|c|}
\hline & \multicolumn{3}{|c|}{ Adoção Parcial - 2007} & \multicolumn{3}{|c|}{ Adoção Total - 2010} & \multicolumn{3}{|c|}{ Amostra Completa } \\
\hline & Preço & Retorno & $\begin{array}{l}\text { Regressão } \\
\text { Completa }\end{array}$ & Preço & Retorno & $\begin{array}{l}\text { Regressão } \\
\text { Completa }\end{array}$ & Preço & Retorno & $\begin{array}{l}\text { Regressão } \\
\text { Completa }\end{array}$ \\
\hline $\begin{array}{l}\text { Lucro } \\
\text { líquido }\end{array}$ & + & 1 & + & - & + & + & + & + & + \\
\hline $\begin{array}{l}\text { Patrimônio } \\
\text { líquido }\end{array}$ & - & / & - & - & + & + & - & + & - \\
\hline
\end{tabular}

Fonte: Elaborada pelos autores.

Nota: (+) indica ganho na relevância da informação, (-) indica redução na relevância da informação e (/) indica existência de apenas um artigo para o período, inviabilizando os cálculos.

\section{CONSIDERAÇÕES FINAIS}

As demonstrações contábeis das companhias passaram por mudanças após a adoção das IFRS. Assim, o objetivo do estudo foi identificar o impacto da adoção das IFRS no value relevance do LL e PL. A literatura apresenta evidências divergentes. Logo, a metodologia adotada para contribuir com o avanço das pesquisas sobre o tema foi uma meta-análise desses estudos. Como resultado, 26 artigos foram avaliados, que englobam 18.562 observações de empresas brasileiras para o período pré IFRS e 17.381 pós IFRS.

As evidências encontradas aceitam a hipótese de que a adoção das IFRS aumenta o value relevance do LL. Todavia, a hipótese de que a adoção das IFRS aumenta o value relevance do PL foi rejeitada, pois os resultados indicam perda da relevância após a adoção das IFRS, conforme encontrado por Ahmed et al. (2013). Os resultados divergem de Damascena et al. (2017), que identificou aumento do value relevance do PL e LL para o modelo de preço. Tal diferença pode derivar do modelo de meta-análise utilizado e da quantidade de estudos a compor a amostra.

O Brasil adotou as IFRS em duas etapas, a primeira em 2007, a segunda etapa em 2010, ocasionando um período de transição nos anos de 2008 e 2009. A análise mostra que para cada fase, o value relevance muda. Para ambas fases, de adoção parcial e total das IFRS, houve redução no value relevance do PL no modelo de preço. Mas em relação ao LL, na primeira fase de adoção das IFRS houve aumento da relevância, enquanto na segunda etapa ocorreu a redução da relevância para o modelo de preço.

Considerando os dois modelos - preço e retorno - combinados, a adoção total das IFRS melhorou o value relevance do LL. Mas no caso do PL, a perda da relevância na primeira fase de adoção parcial, parece ter sido revertida na fase de adoção total. O aumento da relevância do LL pode ser justificado porque a adoção das IFRS aproximou o LL da realidade econômica. Isso ocorre em função da redução no nível de conservadorismo, da inserção das despesas com impairment, dos ganhos em propriedades para investimento (PPI) e outros. Neste cenário, a informação se torna mais relevante para investidores e outros usuários que, muitas vezes, estão interessados na posição mais recente da empresa e no seu potencial de resultados futuros.

Por sua vez, a perda do value relevance do PL pode ter ocorrido porque a adoção total das IFRS permitiu o reconhecimento de resultados abrangentes e ajustes de avaliação patrimonial, que significa resultados que serão materializados somente no futuro. Em termos de avaliação do resultado das companhias, o PL pode ter perdido relevância para esses usuários.

Sugere-se para pesquisas futuras a meta-análise de outras medidas para a qualidade da informação, bem como o estudo mais detalhado das variáveis de controle (por ex., despesas com impairment, ganho com PPI e ajuste de avaliação patrimonial) e de outras relacionadas à características específicas do mercado de capitais brasileiro que podem influenciar o value relevance do PL.

\section{REFERÊNCIAS}

Ahmed, K., Chalmers, K., \& Khlif, H. (2013). A Meta-analysis of IFRS Adoption Effects. The International Journal of Accountings, 48(2),173-217.DOI: https://doi.org/10.1016/j.intacc.2013.04.002

Baioco, V. G., \& Almeida, J. E. F. de. (2017). Efeitos do comitê de auditoria e do conselho fiscal na qualidade da informação contábil no Brasil. Revista de Contabilidade e Finanças, 28(74), 229-248. DOI: http://dx.doi. org/10.1590/1808-057x201703250 
Black, R. \& Nakao, S. H. (2017). Heterogeneidade na qualidade do lucro contábil entre diferentes classes de empresas com a adoção de IFRS: evidências do Brasil. Revista Contabilidade e Finanças, 26(73), 113-131. DOI: https://doi.org/10.1590/1808-057x201702750

Ball, R. (2006). International Financial Reporting Standards (IFRS): pros and cons for investors. Accounting and business research, 36(1), 5-27.

Ball, R. \& Shivakumar, L. (2005). Earnings quality in UK private firms: comparative loos recognition timeliness. Journal of Accounting and Economics, 39, 83-128. DOI: 10.1016/j.jacceco.2004.04.001

Barros, C., M., E., Espejo, M. M. dos, S. B., \& Freitas, A. C. (2013). A relevância da informação contábil no mercado acionário brasileiro: uma análise empírica de companhias listadas na BM\&FBovespa antes e após a promulgação da Lei 11.638/07. Revista Ambiente Contábil, 5(1), 241-262.

Barth, M. E., Beaver, W. H., \& Landsman, W. R. (2001). The relevance of the value relevance literature for financial accounting standard setting: another view. Journal of Accounting \& Economics, 31(1), 77-104.DOI: https://doi.org/10.1016/S0165-4101(01)00019-2

Barth, M. E., Landsman, W. R., \& Lang, M. H. (2008). International Accounting Standards and Accounting Quality. Journal of Accounting Research, 46(3), 467-498. DOI: https://doi.org/10.1111/j.1475-679X.2008.00287.x

Barth, M. E., Landsman, W. R., Young, D., \& Zhuang, Z. (2014). Relevance of Differences between Net Income based on IFRS and Domestic Standards for European Firms. Journal of Business Finance \& Accounting, 41(3-4), 297-327. DOI: https://doi.org/10.1111/jbfa.12067

Bicudo, M. A. V. (2014). Meta-análise: seu significado para a pesquisa qualitativa. Revemat: revista eletrônica de educação matemática, 9, 7-20. DOI: https://doi.org/10.5007/1981-1322.2014v9nespp7

Brasil. Lei $n^{\circ}$. 6.404, de 15 de dezembro de 1976. (1976). Dispõe sobre as Sociedades por Ações. Recuperado em 24 janeiro, 2019 de: < http://www.planalto.gov.br/ccivil_03/leis/L6404compilada.htm>.

Brasil. Lei $n^{\circ}$. 11.638, de 28 de dezembro de 2007. (2007). Altera e revoga dispositivos da Lei $\mathrm{n}^{\circ} 6.404$, de 15 de dezembro de 1976, e da Lei $\mathrm{n}^{\circ} 6.385$, de 7 de dezembro de 1976, e estende às sociedade de grande porte disposições relativas à elaboração e divulgação de demonstrações financeiras. Recuperado em 15 dezembro, 2017 de: < http://www.planalto.gov.br/ccivil_03/_ato2007-2010/2007/lei/111638.htm>.

Brasil. Instrução $C V M n^{\circ}$. 485, de 1 de setembro de 2010. (2010). Altera a instrução CVM n ${ }^{\circ} 457$, de 13 de julho de 2007, que dispõe sobre a elaboração e divulgação das demonstrações financeiras consolidadas, com base no padrão contábil internacional emitido pelo International Accounting Standards - IASB. Recuperado em 05 de junho de 2017 de: < http://www.cvm.gov.br/export/sites/cvm/legislacao/instrucoes/anexos/400/inst485. pdf $>$

Brito, P. das C. (2016). A Relevância da informação contábil após a adoção obrigatória das IFRS no Brasil: uma análise das instituições financeiras listadas na BM\&FBovespa (Dissertação Mestrado). Faculdade de Ciências Contábeis da Universidade Federal da Bahia, Salvador.

Brunozi, A. C., Jr., Ott, E., Coelho, D. M., Menegat, L. A., \& Webber, F. L. (2017). Persistência e Value Relevance dos Resultados Contábeis com a Adoção das IFRS: Um Estudo em Empresas de Países do GLENIF. Enfoque, 36(3), 33-51. DOI: http://dx.doi.org/10.4025/enfoque.v36i3.31820

Callao, S., Jarne, J. I., \& Laínez, J. A. (2007). Adoption of IFRS in Spain: Effect on the comparability and relevance of financial reporting. Journal of International Accounting, Auditing and Taxation, 16, 148-178. DOI: https:// doi.org/10.1016/j.intaccaudtax.2007.06.002

Costa, J. A., \& Afonso, L. E. (2015). O valor preditivo do resultado líquido contábil, dos accruals e do fluxo de caixa operacional das seguradoras. Anais do Congresso USP de Controladoria e Contabilidade, São Paulo, 15.

CPC. Pronunciamento Técnico CPC - 00. (2011). Pronunciamento conceitual básico: estrutura conceitual para a elaboração e apresentação das demonstrações contábeis. Recuperado 21 de Setembro, 2017, de: < http:// www.cpc.org.br/CPC/Documentos-Emitidos/Pronunciamentos/Pronunciamento?Id=80 >.

Damascena, L.G, Duarte, F. C. de L., \& Paulo, E. (2017). Meta-análise dos efeitos da adoção das IFRS na qualidade da informação contábil no Brasil. Revista de Contabilidade do Mestrado em Ciências Contábeis da UERJ, 22(1), 28-48. DOI: https://doi.org/10.12979/31902 
Dias, R. S., Reina, D., Hehr, D. A., \& Almeida, A. A. de. (2015). Análise do impacto da DFC no preço das ações negociadas na Bovespa. Anais do Congresso iberoamericano de contabilidad de gestión, Florianópolis, 9.

Duarte, F. C. L., Girão, L. F. de A. P., \& Paulo, R. (2017). Avaliando Modelos Lineares de Value Relevance: Eles Captam o que Deveriam Captar? Revista de Administração Contemporânea, 21, 110-134. DOI: http://dx.doi. org/10.1590/1982-7849rac2017160202.

Eng, L. L., Lin, J. \& Figueiredo, J. N. De (2014). IFRS Adoption and the Information Environment: Evidence from Brazil. The Second International Conference of the Journal of International Accounting (JIAR), 2. Recuperado 03 de julho, 2018 de: < http://www.af.polyu.edu.hk/conference_pages/detail/23>.

Ferreira, L. V., Lemes, S. \& Forti, C. A. B. (2015). Qualidade Informativa do lucro líquido e do lucro abrangente. Enfoque: Reflexão Contábil, 34(3). DOI: http://dx.doi.org/10.4025/enfoque.v34i3.28183.

Figlioli, B. (2017). A relevância da informação contábil para o mercado de capitais brasileiro sob o pressuposto da racionalidade limitada dos investidores. (Tese Doutorado). Faculdade de Economia, Administração e Contabilidade de Ribeirão Preto da Universidade de São Paulo.

Figueiredo, D. B., Filho, Paranhos, R., Silva, J. A. da, Jr., Rocha, E. C. da, \& Alves, D. P. (2014). O que é, para que serve e como se faz uma meta-análise. Revista Teoria \& Pesquisa, 23(2), 205-228. DOI: http://dx.doi. org/10.4322/tp.2014.018

Francis, J., \& Schipper, K. (1999). Have financial statements lost their relevance?. Journal of Accounting Research, 37(2), 319-352. DOI: http://dx.doi.org/10.2307/2491412

Freire, M. D. M., Machado, M. R. R., Machado, L. S., Souza, E. S., \& Oliveira, J. J. (2012). Aderência às normas internacionais de contabilidade pelas empresas brasileiras. Revista de Contabilidade e Organizações, 6 (15), 3-22. DOI: https://doi.org/10.11606/rco.v6i15.52654

Gonçalves, J. C., Batista, B. L. L., Macedo, M. A. da S., \& Marques, J. A. V. da C. (2014a). Análise do impacto do processo de convergência às normas internacionais de contabilidade no Brasil: um estudo com base na relevância da informação contábil. Revista Universo Contábil, 10(3). DOI: http://dx.doi.org/10.4270/ ruc. $2014325-43$

Gonçalves, J. C., Rodrigues, A., \& Macedo, M. A. da S. (2014b). Poder explicativo de variáveis contábeis no preço das ações das companhias elétricas em ambiente de IFRS. Revista Ambiente Contábil, 6(1), 219-235.

Grillo, F. F., Lachine, T. C., Baioco, V. G., Reina, D., \& Neto, A. S. (2016). Value Relevance: Análise dos efeitos da avaliação a valor justo. Revista ConTexto, 16(32), 94-109.

Hail, L., Leuz, C., \& Wysocki, P. D. (2009). Global accounting convergence and the potential adoption of IFRS by the United States: An analysis of economic and policy factors. Recuperado em 30 de novembro, 2017, de: $<$ https://papers.ssrn.com/sol3/papers.cfm?abstract_id=1357331>.

Holthausen, R. W., \& Watts, R. L. (2001). The relevance of the value-relevance literature for financial accounting standard setting. Journal of Accounting and Economics, 31, 3-75. DOI: https://doi.org/10.1016/S01654101(01)00029-5

IFRS. (2018). Who uses IFRS Standards? Recuperado em 23 de maio, 2018, de: < http://www.ifrs.org/use-aroundthe-world/use-of-ifrs-standards-by-jurisdiction/\#profiles $>$.

Ikuno, L. M., Niyama, J. K., Botelho, \& Santana, C. M. (2012). Contabilidade Internacional: uma análise da produção científica nos principais periódicos internacionais da área - 2000 a 2009. Revista Contabilidade e Organizações, 6 (15),142-163. DOI: https://doi.org/10.11606/rco.v6i15.52661

Jarva, H. \& Lantto, A. M. (2012). Information Contento f IFRS versus Domestic Accounting Standards: Evidence from Finland. SSRN, 141-177. Recuperado 24 de outubro, 2017, de: < https://papers.ssrn.com/sol3/papers. cfm?abstract_id $=1588087>$.

Karampinis, N. \& Hevas, D. (2009). The Effect of the Mandatory Application of IFRS on the Value Relevance of Accounting Data: Some Evidence from Greece. European Research Studies, 12(1), 73-100.

Lourenço, I. C., \& Branco, M. C. (2015 a). A governaça corporativa e o efeito da adoção das IFRS: O caso brasileiro. Revista Universo Contábil, 11, 157-172. DOI: http://dx.doi.org/10.4270/ruc.20151157-172 
Lubave, M. V., Mazzuco, M. A. S., \& Nez, J. de. (2017). A qualidade da informação contábil e a influência do value relevance nas empresas brasileiras da BM\&FBOVESPA: um estudo bibliométrico. Anais do Congresso UFSC de Controladoria e Finanças, Florianópolis, 7.

Macedo, M. A. da S., Araújo, M. B. V. de, \& Braga, J.P. (2012). Impacto do Processo de Convergência às normas Internacionais de Contabilidade na Relevância das Informações Contábeis. Revista de Educação e Pesquisa em Contabilidade, 6(4), 367-382. DOI: https://doi.org/10.17524/repec.v6i4.611

Macedo, M. A. da S., Machado, M. A. V., Machado, M. R. (2013a). Análise da relevância da informação contábil no Brasil num contexto de convergência às normas internacionais de contabilidade. Revista Universo Contábil, 9(1), 65-85. DOI: http://dx.doi.org/10.4270/ruc.20139

Macedo, M. A. da S., Machado, M. A. V., Murcia, F. D. R., \& Machado, M. R. (2011). Análise do impacto da substituição da DOAR pela DFC: um estudo sob a perspectiva do value-relevance. Revista Contabilidade e Finanças, 22(57), 299-318. DOI: https://doi.org/10.1590/S1519-70772011000300005

Macedo, M. A. da S., Machado, M. R., Machado, M. A. V., \& Mendonça, P. H. C. (2013b). Impacto da Conversão às normas Contábeis Internacionais no Brasil Sobre o Conteúdo Informacional da Contabilidade. Revista de Educação e Pesquisa em Contabilidade, 7(3), 222-239. DOI: https://doi.org/10.17524/repec.v7i3.905

Machado, M. A. V., Macedo, M. A. da S., \& Machado, M. R. (2015). Análise da Relevância do Conteúdo Informacional da DVA no Mercado Brasileiro de Capitais. Revista Contabilidade e Finanças, 26(67). DOI: http://dx.doi.org/10.1590/1808-057x201512240

Machado, M. A. V, Silva Filho, A. C. C \& Callados, A. L. C. (2014). O processo de convergência às IFRS e a capacidade do lucro e do fluxo de caixa em prever os fluxos de caixa futuro: evidências no mercado brasileiro. Revista de Contabilidade e Organizações, 21, 5-13. DOI: https://doi.org/10.11606/rco.v8i21.55603

Martins, V. G, Machado, M. A. V. \& Callado, A. L. C. (2014a). Análise da Aditividade de Value Relevance da DFC e da DVA ao Conjunto de Demonstrações Contábeis: Evidencias de Empresas do Mercado de Capitais Brasileiro. Revista Contabilidade, Gestão e Governança, 17(1), 75-94.

Martins, V. G., Oliveira, A. S. de, Niyama, J. K. \& Diniz, J. A. (2014b). Níveis diferenciados de governança corporativa e a qualidade da informação contábil durante o processo de convergência ás normas internacionais de contabilidade. ConTexto, 14(27), 23-42.

Matos, C.A.de.(2011). Uma generalização empírica sobre comunicação boca a boca usando metanálise. $R A C$-Revista de Administração Contemporânea, 15(5). DOI: http://dx.doi.org/10.1590/S1415-65552011000500006.

Niyama, J.K. (2008). Contabilidade Internacional. São Paulo: Atlas.

Ohlson, J. A. (1995). Earnings, book values, and dividends in equity valuation. Contemporary accounting research, 11(2), 661-687. DOI: https://doi.org/10.1111/j.1911-3846.1995.tb00461.X

Potin, S. A., Bortolon, P. M., \& Neto, A. S. (2016). Hedge Accounting no Mercado Acionário Brasileiro: Efeitos na Qualidade da Informação Contábil, Disclosure e Assimetria de Informação. Revista de Contabilidade e Finanças, 27(71). DOI: http://dx.doi.org/10.1590/1808-057x201602430

Ramos, D. A. \& Lustosa, P. R. B. (2013). Verificação Empírica da value relevance na adoção das normas internacionais de contabilidade para o mercado de capitais brasileiro. ConTexto, 13(25), 70-83.

Rodrigues, J. M., Elias, W. G, \& Campos, E. S. (2015). Relevância da informação contábil: uma análise dos efeitos da contabilização dos gastos com pesquisa e desenvolvimento com a aplicação da Lei 11.638/07 no mercado brasileiro. Revista de Contabilidade e Controladoria, 7(3), 131-148. DOI: http://dx.doi.org/10.5380/rcc. v7i3.41555

Rodrigues, J. M., \& Niyama, J. K. (2016). Relevância da informação contábil com a aplicação do padrões internacionais de contabilidade: uma análise a partir de países que compões o G7 e BRICS que já convergiram com os IFRS. Anais do Congresso Brasileiro de Contabilidade, Fortaleza, 20.

Santos, M. A. C. dos, \& Cavalcante, P. R. N. (2014). O Efeito da Adoção dos IFRS sobre a Relevância Informacional do Lucro Contábil no Brasil. Revista de Contabilidade e Finanças, 25(66), 228-241. DOI: http://dx.doi. org/10.1590/1808-057x201410690

Sarlo Neto, A., Teixeira, A. J. C., Loss, L., \& Lopes, A. B. (2005). O diferencial no impacto dos resultados contábeis nas ações ordinárias e preferenciais no mercado brasileiro. Revista de Contabilidade e Finanças, 16 (37), 46-58. http://dx.doi.org/10.1590/S1519-70772005000100004 
Siebel, V. (2013). Relevância dos Indicadores contábeis na determinação do preço das ações no contexto da nova economia: um estudo da América Latina. (Dissertação Mestrado). Faculdade do Vale do Rio dos Sinos, São Leopoldo.

Silva, A. C. da C e Filho, Martins, V. G., \& Machado, M. A. V. (2013). Adoção do valor justo para os ativos biológicos: análise de sua relevância em empresas brasileiras. Revista Universo Contábil, 9(4), 110-127. DOI: http://dx.doi.org/10.4270/ruc.20139

Silva, R. L. M. da. (2013). Adoção completa das IFRS no Brasil: qualidade das demonstrações contábeis e o custo de capital próprio (Tese de Doutorado). Universidade de São Paulo, São Paulo.

Silva, A. da, Brighenti, J., \& Klann, R. C. (2018). Efeitos da Convergência às normas Contábeis Internacionais na Relevância da Informação Contábil de Empresas Brasileiras. Revista Ambiente Contábil 6, 10(1), 121-138. DOI: https://doi.org/10.21680/2176-9036.2018v10n1ID11016

Silva, C. dos A., Conceição, S. H., \& Dourado, G. B. (2015). Análise da adoção no Brasil das normas Internacionais de Contabilidade (IFRS): Um Estudo com base na Relevância da Informação Contábil. Anais do Congresso UFSC de Controladoria e Finanças, Santa Catarina, 6.

Souza, M. M. de, \& Borba, J. A. (2017). Value Relevance do nível de disclosure das combinações de negócios e do goodwill reconhecido na companhias de capital aberto brasileiras. Revista de Contabilidade e Finanças, 28(73), 77-92. DOI: https://doi.org/10.1590/1808-057x201703240

StataCorp. 2015. Stata: Release 14. Statistical Software. College Station, TX: StataCorp LLC.

Zeff, S.A., \& Nobes, C.W. (2010). Commentary: Has Australia (or any other jurisdiction) 'adopted' IFRS? Australian Accounting Review 20(2), 178-184. DOI: https://doi.org/10.1111/j.1835-2561.2010.00089.x.

\section{Como citar este artigo}

Santos, S. M. dos; Lemes, S. \& Barboza, F. L. de M. (2019). O value relevance é relevante?. Revista de Contabilidade e Organizações, 13:e152518. DOI: http://dx.doi.org/10.11606/issn.1982-6486. rco.2019.152518 